\title{
A single institution experience with robotic and laparoscopic distal pancreatectomies
}

\author{
Shi Qing Lee ${ }^{1,2}$, Tousif Kabir ${ }^{1}$, Ye-Xin Koh ${ }^{1}$, Jin-Yao Teo, ${ }^{1,3}$, Ser-Yee Lee ${ }^{1,3}$, \\ Juinn-Huar Kam ${ }^{1,3}$, Peng-Chung Cheow ${ }^{1,3}$, Prema Raj Jeyaraj ${ }^{1,3}$, Pierce K. H. Chow ${ }^{1,3}$, \\ London L. Ooi ${ }^{1,3}$, Alexander Y. F. Chung ${ }^{1,3}$, Chung-Yip Chan ${ }^{1,3}$, and Brian K. P. Goh ${ }^{1,3}$ \\ ${ }^{1}$ Department of Hepatopancreatobiliary and Transplant Surgery, Singapore General Hospital, \\ ${ }^{2}$ Yong Loo Lin School of Medicine, National University of Singapore, \\ ${ }^{3}$ Duke-NUS Medical School, National University of Singapore, Singapore
}

\begin{abstract}
Backgrounds/Aims: This study aims to describe our experience with minimally-invasive distal pancreatectomies, with emphasis on the comparison between robotic distal pancreatectomy (RDP) and laparoscopic distal pancreatectomy (LDP). Methods: Retrospective review of 102 consecutive RDP and LDP from 2006 to 2019 was performed. Results: There were 27 and 75 patients who underwent RDP and LDP, respectively. There were $12(11.8 \%)$ open conversions and $16(15.7 \%)$ patients had major (> grade 2) morbidities. Patients who underwent RDP had significantly higher rates of splenic preservation $(44.4 \%$ vs. $13.3 \%, p=0.002)$, higher rates of splenic-vessel preservation $(40.7 \%$ vs. $9.3 \%$, $\mathrm{p}=0.001$ ), higher median difficulty score ( 5 vs. $3, p=0.002$ ) but longer operation time (385 vs. 245 minutes, $p<0.001)$. The rate of open conversion tended to be lower with $\operatorname{RDP}(3.7 \%$ vs. $14.7 \%, p=0.175)$. Conclusions: In our institution practice, both RDP and LDP were safe and effective. The use of RDP appeared to be complementary to LDP, allowing us to perform more difficult procedures with comparable postoperative outcomes. (Ann Hepatobiliary Pancreat Surg 2020;24:283-291)
\end{abstract}

Key Words: Laparoscopic distal pancreatectomy; Minimally-invasive distal pancreatectomy; Robotic distal pancreatectomy; Left pancreatectomy

\section{INTRODUCTION}

Minimally invasive distal pancreatectomy (MIDP) has become increasingly popular over the last decade cause of its many advantages over the open approach such as the shorter hospital stay, reduced analgesic requirement, and reduced postoperative morbidity. ${ }^{1-3}$ Laparoscopic surgery confers many benefits such as smaller surgical scars, reduced blood loss, and faster recovery times. ${ }^{4-6}$ Nonetheless, its widespread adoption remains restricted due to the technically demanding nature of the MIDP especially with the straight rigid instruments used in conventional laparoscopy.

Presently, with the introduction of the da Vinci Robotic Surgical System (Intuitive Surgical, Inc., Sunnyvale, CA), surgeons can potentially overcome the limitations of traditional laparoscopy due to better dexterity from the patented endo-wrist, three-dimensional (3D) visualization, and better ergonomics. ${ }^{7-12}$ Some studies have shown that robotic surgery is a safe and feasible approach to DP but requires a longer operative time. ${ }^{1,5}$ However, presently there is no consensus on which approach (robotic or laparoscopic) is better as both techniques appear equivalent. $^{10-15}$ This study summarizes our experience with robotic (RDP) and laparoscopic distal pancreatectomies (LDP), comparing between the clinical outcomes of RDP versus LDP.

Received: January 10, 2020; Revised: April 18, 2020; Accepted: April 29, 2020

Corresponding author: Brian K. P. Goh

Department of Hepatopancreatobiliary and Transplant Surgery, Singapore General Hospital, Level 5, 20 College Road, Academia, 169856, Singapore

Tel: +65-63214051, E-mail: bsgkp@hotmail.com

Copyright (C) 2020 by The Korean Association of Hepato-Biliary-Pancreatic Surgery

This is an Open Access article distributed under the terms of the Creative Commons Attribution Non-Commercial License (http://creativecommons.org/ censes/by-nc/4.0) which permits unrestricted non-commercial use, distribution, and reproduction in any medium, provided the original work is properly cited. Annals of Hepato-Biliary-Pancreatic Surgery • pISSN: 2508-5778 • elSSN: 2508-5859 


\section{MATERIALS AND METHODS}

\section{Patients}

We identified 102 consecutive patients from our prospectively maintained database who underwent RDP or LDP at our institution from 2006 to 2019. This study was approved by our institution review board. All patient data were collected retrospectively from the patients' clinical, radiological, and pathological records. The choice of surgical approach was based on multiple factors such as surgeon's and patient's preference, patient's overall fitness, and tumor characteristics. Ultimately, the final decision for a particular treatment approach was made after extensive discussions between the managing clinician and the patient. Cost was a major factor in the decision-making as patients who elected to undergo RDP had to pay additional charges.

\section{Surgical technique}

The operative technique at our institution has been described in detail previously. ${ }^{5,16-18}$ Briefly, at present, RDP was performed using three robotic arms (2 left, 1 right) and the robotic camera system (Da Vinci $\mathrm{Si}$, Intuitive Surgical). The robotic instruments used included a combination of some of the following instruments: harmonic scalpel, cardiere forceps, fenestrated bipolar, hemolok applicator and large needle driver. The bedside assistant used conventional laparoscopic suckers, bowel graspers and endostaplers via a $12-\mathrm{mm}$ assistant ports placed in the left iliac fossa.

LDP was performed using various laparoscopic energy devices over the study period depending on the individual surgeon preference including the Harmonic Scalpel (Ethicon Endo-Surgery, Cincinnati, OH, USA), ENSEAL (Ethicon Endo-Surgery, Cincinnati, OH, USA), LigaSure (Covidien, Boulder, CO, USA) or Thunderbeat (Olympus, Tokyo, Japan). In general, dissection of the pancreas proceeded from the medial to lateral position in most cases except for distal lesions in the pancreatic tail. Endoscopic staplers were used to transect the pancreas and in selected cases these were reinforced with sutures.

\section{Definitions}

We defined subtotal pancreatectomy as when the transection of the pancreas was at neck either at or to the right of the portal vein/splenic vein junction. The definition adopted for an extended pancreatectomy was according to the 2014 International Study Group for Pancreatic Surgery (ISGPS) definition which included any DP with adjacent organ resection such as the stomach, colon, mesocolon, or vascular resection due to local tumor involvement. ${ }^{19}$

The latest 2016 ISGPS classification system for Pancreatic Fistula system ${ }^{20}$ was used to define and grade pancreatic fistulas. A clinically relevant postoperative pancreatic fistula (POPF) is defined as a drain output of any measurable volume of fluid with amylase level greater than 3 times the upper institutional normal serum amylase level, associated with a clinically relevant development/condition related directly to the POPF. Postoperative complications were graded according to the Clavien-Dindo grading system. ${ }^{21}$ All postoperative morbidity was recorded up to as 30 days from surgery or within the same hospital stay regardless of the length of stay. 30-day and 90-day mortalities were also recorded. The difficulty of DP was also classified according to the recent difficulty scoring system (DSS) from Japan ${ }^{22}$ with some minor modifications as reported previously. ${ }^{23}$

\section{Statistical analysis}

All statistical analyses were performed using the computer program Statistical Package for the Social Sciences for Windows, version 20.0 (SPSS Inc, Chicago, IL, USA). Analyses were performed using the Mann-Whitney $U$ test, Chi-squared tests, or Fischer's exact test as appropriate. All statistical tests were 2-sided and $p<0.05$ was considered statistically significant.

\section{RESULTS}

During the study period, 102 patients underwent MIDP at our institution. 27 (26.5\%) patients underwent RDP and 75 (73.5\%) patients underwent LDP. Twenty-three (22.5\%) patients underwent splenic preservation and the median difficulty score was 3 . A total of 12 patients $(11.8 \%)$ required an open conversion to complete the procedure. There were 22 successful SS-DP of which 4 were performed via the Warshaw technique and 18 via the Kimura technique. The median operating time was 280 minutes. Thirty-four (33.3\%) patients experienced a postoperative morbidity. Of these, 16 (15.7\%) patients had major mor- 
bidity, and $20(19.6 \%)$ patients had a clinically significant pancreatic fistula. There was no 30-day mortality and 2 $(2.0 \%)$ 90-day mortalities both in the LDP group. The median postoperative stay was 6 days.

There were 2 90-day reoperations. One was in a patient who underwent RDP and developed an incarcerated port-site hernia during the first week requiring repeat laparoscopic treatment and the other was in a patient who developed a large symptomatic pseudocyst after LDP requiring a cyst-gastrostomy. Details of the 2 90-day mortalities were as follows: The first patient was a 69-year old male with a history of previous kidney transplant on immunosuppression who underwent synchronous laparoscopic gastric resection for gastrointestinal stromal tumor, extended right hemicolectomy for colorectal cancer and distal pancreatosplenectomy for intraductal papillary mucinous neoplasm. He had a grade B pancreatic fistula which was well-controlled by the surgically placed drain. Unfortunately, he developed uncontrolled sepsis from nosocomial pneumonia and eventually demised on postoperative day 73. The second patient was a 70-year old male who suffered from an acute myocardial infarction 3 months before surgery. He underwent distal pancreatosplenectomy for pancreatic adenocarcinoma. During the second week of the postoperative recovery period, he suffered from spontaneous intracranial hemorrhage followed by an acute myocardial infarction, he subsequently deteriorated and demised on postoperative day 69.

Table 1. Comparison between the baseline demographic and perioperative data of 102 patients who underwent RDP versus LDP

\begin{tabular}{|c|c|c|c|c|}
\hline & $\begin{array}{c}\text { Total } \\
(\mathrm{n}=102)\end{array}$ & $\begin{array}{l}\mathrm{RDP} \\
(\mathrm{n}=27)\end{array}$ & $\begin{array}{l}\text { LDP } \\
(\mathrm{n}=75)\end{array}$ & $p$-value \\
\hline Period operated, n (\%) & & & & 0.001 \\
\hline 2006-2012 & $20(19.6)$ & 0 & $20(26.7)$ & \\
\hline 2013-2019 & $82(80.4)$ & $27(100)$ & $55(73.3)$ & \\
\hline Male sex, n (\%) & $45(44.1)$ & $9(33.3)$ & $36(48.0)$ & 0.188 \\
\hline Median age (range), years & $62(19-85)$ & $64(21-85)$ & $61(19-80)$ & 0.196 \\
\hline Symptoms, n (\%) & $32(31.4)$ & $9(33.3)$ & $23(30.7)$ & 0.798 \\
\hline Median BMI (range), $\mathrm{kg} / \mathrm{m}^{2}$ & $23.1(12.6-35.9)$ & $23.1(12.6-30.7)$ & $23.4(15.9-35.9)$ & 0.921 \\
\hline Previous abdominal surgery, n (\%) & $28(27.5)$ & $5(18.5)$ & $23(30.7)$ & 0.225 \\
\hline ASA score, $\mathrm{n}(\%)$ & & & & 0.734 \\
\hline 1 & $15(14.7)$ & $5(18.5)$ & $10(13.3)$ & \\
\hline 2 & $72(70.6)$ & $19(70.4)$ & $53(70.7)$ & \\
\hline 3 & $15(14.7)$ & $3(11.1)$ & $12(16.0)$ & \\
\hline Malignant neoplasm, n (\%) & $21(20.6)$ & $4(14.8)$ & $17(22.7)$ & 0.773 \\
\hline Median tumor size, mm (range) & $30.0(0.0-140.0)$ & $20.0(0.0-75.0)$ & $30.0(2.2-140.0)$ & 0.088 \\
\hline Splenic preservation, n (\%) & $22(21.6)$ & $12(44.4)$ & $10(13.3)$ & 0.002 \\
\hline $\begin{array}{l}\text { Splenic vessel preservation } \\
\text { (Kimura technique), n (\%) }\end{array}$ & $18(17.6)$ & $11(40.7)$ & $7(9.3)$ & 0.001 \\
\hline RAMPS, n (\%) & $10(9.8)$ & $4(14.8)$ & $6(8.0)$ & 0.449 \\
\hline Subtotal (resection at / right of PV), n (\%) & $32(31.4)$ & $16(59.3)$ & $16(21.3)$ & $<0.001$ \\
\hline Extended pancreatectomy, n (\%) & $4(3.9)$ & $3(11.1)$ & $1(1.3)$ & 0.056 \\
\hline $\begin{array}{l}\text { Concomitant surgery } \\
\text { (non-cholecystectomy), n (\%) }\end{array}$ & $5(4.9)$ & $1(3.7)$ & $4(5.3)$ & 0.737 \\
\hline Left-sided portal hypertension, n (\%) & $7(6.9)$ & $1(3.7)$ & $6(8.0)$ & 0.672 \\
\hline $\begin{array}{l}\text { Tumor extension to } \\
\text { peripancreatic tissue, } \mathrm{n}(\%)\end{array}$ & $43(42.2)$ & $14(51.9)$ & $29(38.7)$ & 0.234 \\
\hline Tumor close to major vessel, $\mathrm{n}(\%)$ & $46(45.1)$ & $17(63.0)$ & $29(38.7)$ & 0.030 \\
\hline Median difficulty score, range & $3(1-12)$ & $5(1-9)$ & $3(1-12)$ & 0.002 \\
\hline Difficulty, n (\%) & & & & 0.051 \\
\hline Low & $53(52.0)$ & $10(37.0)$ & $43(57.3)$ & \\
\hline Intermediate & $33(32.4)$ & $9(33.3)$ & $24(32.0)$ & \\
\hline High & $16(15.7)$ & $8(29.6)$ & $8(10.7)$ & \\
\hline
\end{tabular}

BMI, body mass index; ASA, American Society of Anesthesiologists; RAMPS, radical antegrade modular pancreatosplenectomy; $\mathrm{PV}$, portal vein 
Table 2. Comparison between the perioperative outcomes of patients who underwent RPD vs. LDP

\begin{tabular}{|c|c|c|c|c|}
\hline & $\begin{array}{c}\text { Total } \\
(\mathrm{n}=102)\end{array}$ & $\begin{array}{l}\mathrm{RDP} \\
(\mathrm{n}=27)\end{array}$ & $\begin{array}{l}\text { LDP } \\
(\mathrm{n}=75)\end{array}$ & $p$-value \\
\hline Open conversion, $\mathrm{n}(\%)$ & $12(11.8)$ & $1(3.7)$ & $11(14.7)$ & 0.175 \\
\hline Median operating time (range), min & $280(85-775)$ & $385(215-775)$ & $245(85-475)$ & $<0.001$ \\
\hline Median blood loss (range), $\mathrm{ml}$ & $100(10-2000)$ & $200(50-1200)$ & $100(10-1990)$ & 0.290 \\
\hline Intraoperative blood transfusion, $\mathrm{n}(\%)$ & $10(9.8)$ & $3(11.1)$ & $7(9.3)$ & 0.722 \\
\hline Postoperative morbidity, n (\%) & $34(33.3)$ & $8(29.6)$ & $26(34.7)$ & 0.634 \\
\hline $\begin{array}{l}\text { Major morbidity (Clavien-Dindo grade }>2) \text {, } \\
\mathrm{n}(\%)\end{array}$ & $16(15.7)$ & $3(11.1)$ & $13(17.3)$ & 0.550 \\
\hline Biochemical fistula, n (\%) & $33(32.4)$ & $6(22.2)$ & $27(36.0)$ & 0.189 \\
\hline Grade $\mathrm{B} / \mathrm{C}$ pancreatic fistula, $\mathrm{n}(\%)$ & $20(19.6)$ & $3(11.1)$ & $17(22.7)$ & 0.195 \\
\hline $\begin{array}{l}\text { Pancreatic fistula requiring } \\
\text { percutaneous drainage, } \mathrm{n}(\%)\end{array}$ & $15(14.7)$ & $2(7.4)$ & $13(17.3)$ & 0.343 \\
\hline Reoperation, n (\%) & $2(2.0)$ & $1(3.7)$ & $1(1.3)$ & 0.461 \\
\hline 30-day mortality, n (\%) & $0(0.0)$ & $0(0.0)$ & $0(0.0)$ & $\mathrm{NC}$ \\
\hline 90-day mortality, n (\%) & $2(2.0)$ & $0(0.0)$ & $2(2.7)$ & 1.000 \\
\hline Median postoperative stay (range), days & $6(3-73)$ & $6(3-26)$ & $6(3-73)$ & 0.548 \\
\hline Readmission, n (\%) & $21(20.6)$ & $4(14.9)$ & $17(22.7)$ & 0.387 \\
\hline
\end{tabular}

\section{Comparison between 27 RDP and 75 LDP (Tables 1, 2)}

The comparison between the baseline demographics, clinicopathological features, and outcomes of these patients are summarized in Tables 1, 2. There was no significant difference in the demographics and clinicopathological features between both groups. Patients who underwent RDP were significantly more likely to be operated during the recent time period (2013-2019) compared to LDP [27 (100\%) vs. 55 (73.3\%), $p=0.001]$ (Table 1).

Patients who underwent RDP had a significantly higher rate of splenic preservation $(44.4 \%$ vs. $13.3 \%, p=0.002)$, higher rate of splenic vessel preservation $(40.7 \%$ vs. $9.3 \%$, $p=0.001)$, higher rate of subtotal resection $(59.3 \%$ vs. $21.3 \%, p<0.001)$, increased frequency of tumor located close to a major vessel $(63.0 \%$ vs. $38.7 \%, p=0.030)$, higher median difficulty score ( 5 vs. $3, p=0.002$ ), and longer operation time (385 minutes vs. 248 minutes, $p<0.001$ ) compared to LDP. Patients who underwent RDP also tended to have non-statistically significant higher rate of extended pancreatectomy $(11.1 \%$ vs. $1.3 \%, p=0.056)$ but lower open conversion rate $(3.7 \%$ vs. $14.7 \%, p=0.175)$.

There was no significant difference in the other periand postoperative outcomes such as transfusion rates, postoperative length of stay, postoperative morbidity, and mortality rate.

\section{Comparison between RDP and LDP in patients with benign or premalignant pancreatic tumors in 79 patients}

A total of 79 patients had benign/premalignant tumors. 23 (29.1\%) patients underwent RDP and 56 (70.9\%) patients underwent LDP. The comparison between the baseline demographics, clinicopathological features, and outcomes of patients with benign or premalignant pancreatic tumors are summarized in Tables 3, 4. There was no significant difference in the demographics and clinicopathological features of both groups. However, patients who underwent RDP tended to have smaller median tumor size (18.0 mm vs. $30.5 \mathrm{~mm}, p=0.071$ ).

Similarly, compared to patients who underwent LDP, patients who underwent RDP had a significantly higher rate of splenic preservation $(52.2 \%$ vs. $17.9 \%, p=0.005)$, higher rate of splenic vessel preservation $(47.8 \%$ vs. $12.5 \%, p=0.004)$, higher rate of subtotal resection $(52.2 \%$ vs. $14.3 \%, p<0.001)$, and higher median difficulty score ( 5 vs. $2, p=0.004$ ). Patients in the RDP group tended to have tumor located close to a major vessel $(56.5 \%$ vs. $33.9 \%, p=0.063)$. There was no significant difference in the other perioperative factors between the two groups. A total of 8 patients $(10.1 \%)$ had open conversion. This rate tended to be higher in patients who underwent LDP (12.5\% vs. $4.3 \%, p=0.426)$. The operating time for patients who under RDP was significant longer than that for LDP (380 minutes vs. 230 minutes, $p<0.001$ ). One $(1.8 \%)$ 
Table 3. Comparison between the baseline demographic and perioperative data of patients who underwent RDP versus LDP for benign/premalignant tumors

\begin{tabular}{|c|c|c|c|c|}
\hline & $\begin{array}{l}\text { Total } \\
\mathrm{n}=79\end{array}$ & $\begin{array}{l}\mathrm{RDP} \\
\mathrm{n}=23\end{array}$ & $\begin{array}{l}\text { LDP } \\
\mathrm{n}=56\end{array}$ & $p$-value \\
\hline Male sex, n (\%) & $37(46.8)$ & $9(39.1)$ & $28(50.0)$ & 0.379 \\
\hline Median age (range), yrs & $60(19-80)$ & $63(21-79)$ & $58.5(19-80)$ & 0.326 \\
\hline Symptoms, n (\%) & $24(30.4)$ & $6(26.1)$ & $18(32.1)$ & 0.595 \\
\hline Median BMI (range), $\mathrm{kg} / \mathrm{m}^{2}$ & $23.2(15.9-35.9)$ & $23.1(17.1-30.7)$ & $23.7(15.9-35.9)$ & 0.974 \\
\hline Previous abdominal surgery, n (\%) & $20(25.3)$ & $4(17.4)$ & $16(28.6)$ & 0.299 \\
\hline ASA score, $\mathrm{n}(\%)$ & & & & 0.852 \\
\hline 1 & $12(15.2)$ & $4(17.4)$ & $8(14.3)$ & \\
\hline 2 & $58(73.4)$ & $17(73.9)$ & $41(73.2)$ & \\
\hline 3 & $9(11.4)$ & $2(8.7)$ & $7(12.5)$ & \\
\hline Median tumor size, mm (range) & $27.0(0.0-140.0)$ & $18.0(0.0-75.0)$ & $30.5(2.2-140.0)$ & 0.071 \\
\hline Splenic preservation, $\mathrm{n}(\%)$ & $22(57.8)$ & $12(52.2)$ & $10(17.9)$ & 0.004 \\
\hline $\begin{array}{l}\text { Splenic vessel preservation } \\
\text { (Kimura technique), n (\%) }\end{array}$ & $18(22.8)$ & $11(47.8)$ & $7(12.5)$ & 0.004 \\
\hline Subtotal (resection at/ right of PV), n (\%) & $20(25.3)$ & $12(52.2)$ & $8(14.3)$ & $<0.001$ \\
\hline $\begin{array}{l}\text { Concomitant surgery } \\
\text { (non-cholecystectomy), n (\%) }\end{array}$ & $2(2.5)$ & $0(0.0)$ & $2(3.6)$ & 1.000 \\
\hline Left-sided portal hypertension, $\mathrm{n}(\%)$ & $4(5.1)$ & $1(4.3)$ & $3(5.4)$ & 1.000 \\
\hline Tumor extension to peripancreatic tissue, $\mathrm{n}(\%)$ & $32(40.5)$ & $11(47.5)$ & $21(37.5)$ & 0.396 \\
\hline Tumor close to major vessel, $\mathrm{n}(\%)$ & $32(40.5)$ & $13(56.5)$ & $19(33.9)$ & 0.063 \\
\hline Median difficulty score, (range) & $3(1-10)$ & $5(1-9)$ & $2(1-10)$ & 0.004 \\
\hline Difficulty, n (\%) & & & & 0.138 \\
\hline Low & $45(57.0)$ & $10(43.5)$ & $35(62.5)$ & \\
\hline Intermediate & $27(34.2)$ & $9(39.1)$ & $18(32.1)$ & \\
\hline High & $7(8.9)$ & $4(17.4)$ & $3(5.4)$ & \\
\hline
\end{tabular}

BMI, body mass index; ASA, American Society of Anesthesiologists; PV, portal vein

Table 4. Comparison between the perioperative and oncologic outcomes of patients who underwent RPD vs. LDP for benign/premalignant pancreatic tumors

\begin{tabular}{lcccc}
\hline & $\begin{array}{l}\text { Total } \\
\mathrm{n}=79\end{array}$ & $\begin{array}{l}\mathrm{RDP} \\
\mathrm{n}=23\end{array}$ & \multicolumn{1}{c}{$\begin{array}{c}\text { LDP } \\
\mathrm{n}=56\end{array}$} & $p$-value \\
\hline Open conversion, $\mathrm{n}(\%)$ & $8(10.1)$ & $1(4.3)$ & $7(12.5)$ & 0.426 \\
Median operating time (range), min & $250(85-685)$ & $380(215-685)$ & $230(85-475)$ & $<0.001$ \\
Median blood loss (range), ml & $100(10-2000)$ & $200(50-1200)$ & $100(10-2000)$ & 0.232 \\
Intraoperative blood transfusion, n (\%) & $7(8.9)$ & $2(8.7)$ & $5(8.9)$ & 1.000 \\
Postoperative morbidity, n (\%) & $25(31.6)$ & $6(26.1)$ & $19(33.9)$ & 0.496 \\
Major morbidity (Clavien-Dindo grade $>$ 2), & $12(15.2)$ & $2(8.7)$ & $10(17.9)$ & 0.492 \\
n (\%) & $25(31.6)$ & $5(21.7)$ & $20(35.7)$ & 0.225 \\
Biochemical fistula, n (\%) & $16(20.3)$ & $3(13.0)$ & $13(23.2)$ & 0.372 \\
Grade B/C pancreatic fistula, n (\%) & $12(15.2)$ & $2(8.7)$ & $10(17.9)$ & 0.492 \\
Pancreatic fistula requiring & & & \\
percutaneous drainage, n (\%) & $0(0.0)$ & $0(0.0)$ & $0(0.0)$ & $\mathrm{NC}$ \\
Reoperation, n (\%) & $0(0.0)$ & $0(0.0)$ & $0(0.0)$ & $\mathrm{NC}$ \\
30-day mortality, n (\%) & $1(1.3)$ & $0(0.0)$ & $1(1.8)$ & 1.000 \\
90-day mortality, n (\%) & $6(3-73)$ & $6(3-22)$ & $6(3-73)$ & 0.805 \\
Median postoperative stay (range), days & $15(19.0)$ & $3(13.0)$ & $12(21.4)$ & 0.533 \\
Readmission, n (\%) & & &
\end{tabular}

patient in the LDP group died within 90 days of surgery. However, there was no significant difference in the other postoperative outcomes.

\section{DISCUSSION}

Robotic surgery theoretically retains the advantages of 
the laparoscopic approach in terms of smaller surgical scars, faster recovery, with the additional advantage of stable articulating instruments coupled with a magnified 3D high-definition view. ${ }^{1,9}$ The main theoretical advantage of the robotic arms is the increased dexterity from the patented Endowrist technology.

During MIDP, the increased dexterity of the robotic arms has been shown to facilitate suturing and fine dissection in tight spaces allowing for more precise dissection of the splenic vessels from the pancreatic parenchyma. ${ }^{2,11,12,24}$ These advantages have been shown to enable surgeons to perform splenic vessel preservation during MIDP. ${ }^{1,2,10,14,24-26}$ The results of our study also seem to support this hypothesis. In this study, patients who underwent RDP had a significantly higher splenic preservation rate and splenic vessel preservation rate. It is important to add that the decision for splenic preservation, however, is also dependent on the preoperative indications for DP and individual surgeon preference. Indications for DP associated with malignancy may necessitate splenic resection for better oncological outcomes. Nonetheless, subgroup analysis of only benign/premalignant tumors in this study still demonstrated significantly higher rates of splenic preservation and splenic vessel preservation in the RDP group. The RDP group also had a significantly higher rate of subtotal resection and tumor located close to major vessel compared to LDP. Nonetheless, it is important to highlight that selection bias whereby surgeons may have preferred the robotic platform for patients planned for splenic preservation, may have also accounted for the higher spleen-preservation rate. ${ }^{24}$ Other confounding factors such as location of tumor (proximity to splenic hilum) may also affect the surgeon's decision to attempt splenic preservation.

Another postulated advantage of RDP is its lower conversion rate to open surgery compared to LDP. ${ }^{2,10,14,24,25}$ This is because robotic assistance potentially provides technical advantages such as motion scaling and stabilization as well as reduced operator fatigue, which facilitates hemostasis and control of the vascular structures surrounding the pancreas. ${ }^{24}$ In our study, common indications for conversion to open surgery include intraoperative bleeding and tumor extension. These intraoperative complications could be better controlled with robotic surgery, reducing the need for open conversion. Nonetheless, while our results show that the rate of conversion tended to be lower for RDP than LDP ( $3.7 \%$ vs. $14.7 \%, p=0.175)$, this difference was not statistically significant. Possible confounding factors such as different stages of learning curve and different surgeons' experience with minimally invasive surgery may also have contributed to these findings. Of note, RDP was only adopted only during the latter study period (2013-2019) whereby our institution already had prior experience with LDP. This important confounding factor likely partially contributed to the superior results observed with RDP as surgeons in our institution had already overcome part of the learning curve for MIDP via performing LDP before embarking on $\mathrm{RDP}^{27,28}$ It is well-known from the literature that the open conversion rate of MIDP is higher during a surgeon's initial learning curve. $^{29}$

In this study, subtotal pancreatectomy was performed significantly more frequently for tumors located in the neck or body via the robotic approach. Some surgeons may propose central pancreatectomy as a parenchymasaving approach for these tumors especially when these tumors are not suggestive of invasive cancer. ${ }^{30,31}$ However, in our practice we prefer to perform left-sided pancreatectomy over central pancreatectomy for tumors in these locations as despite the advantages of preserving pancreatic endocrine and exocrine function in the long-term, central pancreatectomy is associated with a higher shortterm risk of major morbidity especially a clinically-significant postoperative pancreatic fistula which may potentially be life-threatening. ${ }^{30,31}$

A frequent disadvantage of robotic surgery reported by many authors is the longer operation time for RDP compared to LDP. ${ }^{1,2,5,12,14,32}$ Similarly, our study also demonstrated that the operative time was significantly longer with RDP. The longer operation time with RDP can be attributed to the longer docking time and increased time to perform exchange of instruments which has been shown to be improve when surgeons gain increasing experience with the robotic platform. ${ }^{1,2,5,12,32}$ Based on current literature, it has been suggested that a surgeon would require 7 to 40 cases to overcome the learning curve for RDP when he/she had no prior experience with robotic surgery. ${ }^{33-35}$ In our experience, this unavoidable learning phase of RDP may have contributed to the longer operative time. Nonetheless, practice and familiarity with the 
robotic platform, in conjunction with standardization of the surgical technique are likely to reduce the length of the learning curve for RDP. ${ }^{12,28,35-38}$ Hence, contrary to most studies, some investigators have demonstrated that RDP is associated with a shorter operating time. ${ }^{8}$

A significant barrier to robotic surgery today is the cost of adopting the procedure. ${ }^{18,32}$ In this study, cost was a major factor determining the type of minimally invasive surgery adopted as patients had to pay an additional amount of about $\mathrm{S} \$ 5000$ for robotic assisted procedures. ${ }^{32}$ While the cost of robotic surgery varies between institutions and countries, it is uniformly higher than conventional laparoscopic surgery. As the cost of purchasing and maintain the robot is also significant, relatively few surgeons globally have regular access to the robotic technology for training, contributing to the lack of familiarity and experience with the system. ${ }^{18,24}$ Hence, the barrier to introduce robotic surgery to many institutions worldwide is relatively high. However, it is important to note that the costs of robotic systems will likely decrease in the near future with increasing availability and competition in the market. ${ }^{18,24,39}$

Many investigators have demonstrated the safety and feasibility of RDP in comparison with LDP as the incidence of total postoperative complications were similar between the two. ${ }^{1,2}$ Similarly, the results of our study showed no significant difference between RDP and LDP in terms of the frequency of total complications, major morbidity, pancreatic fistula, and readmission rate. RDP also did not increase the reoperation rates and length of hospital stay.

The main limitations of the present study are its relatively small sample size and its retrospective nature. Hence, it may be subject to Type 1 or 2 errors. Similarly, various other confounding factors such as operative indications, surgeon experience, and patient preference could have also affected outcomes. Selection bias was also likely a major confounder influencing the study results. Nonetheless, the results of the present study reflect the real-world situation whereby surgeons at our institution tended to select more difficult MIDP such as spleen preserving procedures for RDP.

In conclusion, the findings of this study suggest that both RDP and LDP can be safely adopted. The use of RDP appeared to be complementary to LDP in our institution, allowing us to expand our indications for MIDP to more technically difficult procedures such as spleen-saving pancreatectomies with comparable postoperative outcomes.

\section{ACKNOWLEDGEMENTS}

Dr Goh BK has received travel grants and honorarium from Transmedic the local distributor of the Da Vinci robotic platform, Johnson and Johnson, Medtronic and Baxter.

\section{CONFLICT OF INTEREST}

There are no sources of funding associated with this manuscript.

\section{ORCID}

Shi Qing Lee: https://orcid.org/0000-0003-4142-5366

Tousif Kabir: https://orcid.org/0000-0002-3364-3147

Ye-Xin Koh: https://orcid.org/0000-0001-5006-4174

Jin-Yao Teo: https://orcid.org/0000-0002-0777-8128

Ser-Yee Lee: https://orcid.org/0000-0001-9119-7408

Juinn-Huar Kam: https://orcid.org/0000-0002-2478-9689

Peng-Chung Cheow:

https://orcid.org/0000-0002-8102-1203

Prema Raj Jeyaraj:

https://orcid.org/0000-0003-3200-6450

Pierce K. H. Chow:

https://orcid.org/0000-0003-4142-5366

London L. Ooi: https://orcid.org/0000-0001-6777-8464

Alexander Y. F. Chung:

https://orcid.org/0000-0002-4598-6139

Chung-Yip Chan: https://orcid.org/0000-0002-9397-0908

Brian K. P. Goh: https://orcid.org/0000-0001-8218-4576

\section{AUTHOR CONTRIBUTIONS}

Conceptualization: SQL, TK, BKPG. Data curation: SQL, TK, YXK, JYT, SYL, JHK. Formal analysis: SQL, TK, YXK, BKPG. Funding acquisition: Nil. Methodology: SQL, JYT, SYL, JHK, CYC, BKPG. Project administration: PCC, PRJ, PKHC, LLO, AYFC, CYC. Visualization: PCC, PRJ, PKHC, LLO, AYFC, CYC. Writing - original draft: SQL, TK, YXK, JYT. Writing - review \& editing: SYL, JHK, PCC, PRJ, PKHC, LLO, AYFC, CYC, BKPG. 


\section{REFERENCES}

1. Niu X, Yu B, Yao L, Tian J, Guo T, Ma S, et al. Comparison of surgical outcomes of robot-assisted laparoscopic distal pancreatectomy versus laparoscopic and open resections: a systematic review and meta-analysis. Asian J Surg 2019;42:32-45.

2. Guerrini GP, Lauretta A, Belluco C, Olivieri M, Forlin M, Basso $\mathrm{S}$, et al. Robotic versus laparoscopic distal pancreatectomy: an up-to-date meta-analysis. BMC Surg 2017;17:105.

3. Hua Y, Javed AA, Burkhart RA, Makary MA, Weiss MJ, Wolfgang CL, et al. Preoperative risk factors for conversion and learning curve of minimally invasive distal pancreatectomy. Surgery 2017;162:1040-1047.

4. Zeng G, Teo NZ, Goh BKP. Short-term outcomes of minimally invasive surgery for patients presenting with suspected gallbladder cancer: report of 8 cases. J Minim Access Surg 2018;15: 109-114.

5. Goh BK, Chan CY, Soh HL, Lee SY, Cheow PC, Chow PK, et al. A comparison between robotic-assisted laparoscopic distal pancreatectomy versus laparoscopic distal pancreatectomy. Int $\mathrm{J}$ Med Robot 2017. doi: 10.1002/rcs.1733. [in press]

6. Edwin B, Sahakyan MA, Abu Hilal M, Besselink MG, Braga M, Fabre JM, et al. Laparoscopic surgery for pancreatic neoplasms: the European association for endoscopic surgery clinical consensus conference. Surg Endosc 2017;31:2023-2041.

7. Kamarajah SK, Sutandi N, Robinson SR, French JJ, White SA. Robotic versus conventional laparoscopic distal pancreatic resection: a systematic review and meta-analysis. HPB (Oxford) 2019;21:1107-1118.

8. Daouadi M, Zureikat AH, Zenati MS, Choudry H, Tsung A, Bartlett DL, et al. Robot-assisted minimally invasive distal pancreatectomy is superior to the laparoscopic technique. Ann Surg 2013;257:128-132.

9. Fruscione M, Pickens R, Baker EH, Cochran A, Khan A, Ocuin $\mathrm{L}$, et al. Robotic-assisted versus laparoscopic major liver resection: analysis of outcomes from a single center. HPB (Oxford) 2019;21:906-911.

10. Gavriilidis P, Lim C, Menahem B, Lahat E, Salloum C, Azoulay D. Robotic versus laparoscopic distal pancreatectomy - the first meta-analysis. HPB (Oxford) 2016;18:567-574.

11. Royall NA, Walsh RM. Robotic distal pancreatectomy and splenectomy: rationale and technical considerations. J Vis Surg 2017; $3: 135$.

12. Lee SY, Allen PJ, Sadot E, D'Angelica MI, DeMatteo RP, Fong Y, et al. Distal pancreatectomy: a single institution's experience in open, laparoscopic, and robotic approaches. J Am Coll Surg 2015;220:18-27.

13. Lyman WB, Passeri M, Sastry A, Cochran A, Iannitti DA, Vrochides D, et al. Robotic-assisted versus laparoscopic left pancreatectomy at a high-volume, minimally invasive center. Surg Endosc 2019;33:2991-3000.

14. Zhou JY, Xin C, Mou YP, Xu XW, Zhang MZ, Zhou YC, et al. Robotic versus laparoscopic distal pancreatectomy: a metaanalysis of short-term outcomes. PLoS One 2016;11:e0151189.

15. Maggino L, Malleo G, Salvia R, Bassi C, Vollmer CM Jr. Defining the practice of distal pancreatectomy around the world. HPB (Oxford) 2019;21:1277-1287.

16. Goh BKP, Lee SY, Kam JH, Soh HL, Cheow PC, Chow PKH, et al. Evolution of minimally invasive distal pancreatectomies at a single institution. J Minim Access Surg 2018;14:140-145.

17. Goh BKP, Chan CY, Lee SY, Chan WH, Cheow PC, Chow $\mathrm{PKH}$, et al. Factors associated with and consequences of open conversion after laparoscopic distal pancreatectomy: initial expe- rience at a single institution. ANZ J Surg 2017;87:E271-E275.

18. Goh BKP, Low TY, Lee SY, Chan CY, Chung AYF, Ooi LLPJ. Initial experience with robotic pancreatic surgery in Singapore: single institution experience with 30 consecutive cases. ANZ J Surg 2019;89:206-210.

19. Hartwig W, Vollmer CM, Fingerhut A, Yeo CJ, Neoptolemos JP, Adham M, et al. Extended pancreatectomy in pancreatic ductal adenocarcinoma: definition and consensus of the International Study Group for Pancreatic Surgery (ISGPS). Surgery 2014;156: $1-14$.

20. Bassi C, Marchegiani G, Dervenis C, Sarr M, Abu Hilal M, Adham M, et al. The 2016 update of the International Study Group (ISGPS) definition and grading of postoperative pancreatic fistula: 11 Years After. Surgery 2017;161:584-591.

21. Dindo D, Demartines N, Clavien PA. Classification of surgical complications: a new proposal with evaluation in a cohort of 6336 patients and results of a survey. Ann Surg 2004;240:205213.

22. Ohtsuka T, Ban D, Nakamura Y, Nagakawa Y, Tanabe M, Gotoh $\mathrm{Y}$, et al. Difficulty scoring system in laparoscopic distal pancreatectomy. J Hepatobiliary Pancreat Sci 2018;25:489-497.

23. Goh BKP, Kabir T, Koh YX, Teo JY, Lee SY, Kam JH, et al. External validation of the Japanese difficulty scoring system for minimally-invasive distal pancreatectomies. Am J Surg 2019;218: 967-971.

24. Teo RYA, Goh BKP. Surgical resection of pancreatic neuroendocrine neoplasm by minimally invasive surgery-the robotic approach? Gland Surg 2018;7:1-11.

25. Huang B, Feng L, Zhao J. Systematic review and meta-analysis of robotic versus laparoscopic distal pancreatectomy for benign and malignant pancreatic lesions. Surg Endosc 2016;30:40784085 .

26. Chen S, Zhan Q, Chen JZ, Jin JB, Deng XX, Chen H, et al. Robotic approach improves spleen-preserving rate and shortens postoperative hospital stay of laparoscopic distal pancreatectomy: a matched cohort study. Surg Endosc 2015;29:3507-3518.

27. Goh BK. Robot-assisted minimally invasive distal pancreatectomy is superior to the laparoscopic technique. Ann Surg 2016; 263:e49.

28. Kang CM. Is robot-assisted minimally invasive distal pancreatectomy superior to the laparoscopic technique? Ann Surg 2015;261:e153-e154.

29. Goh BKP, Kabir T, Koh YX, Teo JY, Lee SY, Kam JH, et al. Critical appraisal of the impact of individual surgeon experience on the outcomes of minimally invasive distal pancreatectomies: collective experience of multiple surgeons at a single institution. Surg Laparosc Endosc Percutan Tech 2020. doi: 10.1097/SLE. 0000000000000800. [in press]

30. Kang CM, Kim DH, Lee WJ, Chi HS. Initial experiences using robot-assisted central pancreatectomy with pancreaticogastrostomy: a potential way to advanced laparoscopic pancreatectomy. Surg Endosc 2011;25:1101-1106.

31. Chen S, Zhan Q, Jin JB, Wu ZC, Shi Y, Cheng DF, et al. Robot-assisted laparoscopic versus open middle pancreatectomy: short-term results of a randomized controlled trial. Surg Endosc 2017;31:962-971.

32. Low TY, Goh BKP. Initial experience with minimally invasive extended pancreatectomies for locally advanced pancreatic malignancies: report of six cases. J Minim Access Surg 2019;15: 204-209.

33. Shyr BU, Chen SC, Shyr YM, Wang SE. Learning curves for robotic pancreatic surgery-from distal pancreatectomy to pancreaticoduodenectomy. Medicine (Baltimore) 2018;97:e13000.

34. Barrie J, Ammori BJ. Minimally invasive distal pancreatectomy: 
a single-center analysis of outcome with experience and systematic review of the literature. Surg Laparosc Endosc Percutan Tech 2015;25:297-302.

35. Shakir M, Boone BA, Polanco PM, Zenati MS, Hogg ME, Tsung A, et al. The learning curve for robotic distal pancreatectomy: an analysis of outcomes of the first 100 consecutive cases at a high-volume pancreatic centre. HPB (Oxford) 2015;17:580-586.

36. Braga M, Ridolfi C, Balzano G, Castoldi R, Pecorelli N, Di Carlo V. Learning curve for laparoscopic distal pancreatectomy in a high-volume hospital. Updates Surg 2012;64:179-183.

37. Goh BK, Low TY, Koh YX, Lee SY, Teo JY, Kam JH, et al.
Changing trends and outcomes associated with the adoption of minimally invasive pancreatic surgeries: a single institution experience with 150 consecutive procedures in Southeast Asia. J Minim Access Surg 2019. doi: 10.4103/jmas.JMAS_127_19. [in press]

38. Zureikat AH, Moser AJ, Boone BA, Bartlett DL, Zenati M, Zeh HJ 3rd. 250 robotic pancreatic resections: safety and feasibility. Ann Surg 2013;258:554-559; discussion 559-562.

39. Goh BK, Teo RY. Current status of laparoscopic and robotic pancreatic surgery and its adoption in Singapore. Ann Acad Med Singapore 2020;49:377-382. 